\title{
Research on the Higher Vocational Medicine Production Technology Cultivation Mode of Modern Apprenticeship Talents based on the Integration of Production and Education
}

\author{
Juan Wang ${ }^{1, a_{*}}$, Kejia Wang ${ }^{1, b}$, Yanling Ren ${ }^{1, c}$ \\ ${ }^{1}$ Guizhou Light Industry Technical College, Guiyang, Guizhou, 550025 \\ ${ }^{a \star}$ email, ${ }^{b}$ email, ${ }^{c}$ email
}

Keywords: Production and Education Integration, Vocational Education, Pharmaceutical Production Technology, Modern Apprenticeship, Personnel Training Mode

\begin{abstract}
With the continuous development of Chinese economy, people's living standards have been fully improved, while the demand for the use of drugs also showed a rising trend. From the management of pharmaceutical enterprises and the development of regional economy, the further development of modern apprenticeship training mode of pharmaceutical production technology has played a crucial role in pharmaceutical production. In this paper, through the analysis and analysis of Chinese modern apprenticeship training model to promote the situation, in the vocational colleges to carry out modern apprenticeship talent training mode experience, vocational colleges to develop modern apprenticeship training model problems and solutions The three main aspects of the program, aimed at the comprehensive integration of education in the context of a comprehensive scientific and rational production of modern vocational medicine production technology professional modern apprenticeship training model to strengthen the students' drug production and production capacity, so as to Chinese pharmaceutical companies Cultivate professional and practical high-quality personnel, and further promote Chinese pharmaceutical companies to be stable and healthy operation and development.
\end{abstract}

\section{Introduction}

At present, China has put forward the corresponding modern apprenticeship pilot work, a comprehensive scientific and scientific in different regions to start "enrollment is recruitment, school entrance is the work of the factory, the school business training professionals" as the core content of the pilot [1]. Many vocational colleges on the country put forward the corresponding policy of a positive response to the vocational colleges of the pharmaceutical production technology professional teachers on the modern apprenticeship of the methods and ways to conduct a comprehensive exploration, which in the professional curriculum to establish a " Teaching and learning integration, "the modern apprenticeship training model, the process of training to enhance students' innovative entrepreneurial ability as the main guide, a comprehensive teaching and learning through words and deeds to enable students to master the modern drug production technology.

\section{Chinese Modern Apprenticeship Training Model to Promote the Situation Analysis}

In the vocational colleges in the pharmaceutical production technology is mainly based on the original biopharmaceutical technology as a prototype, on the basis of innovation and transformation, in the past few years, bio-pharmaceutical technology has been the country into the ranks of key construction, And also Chinese financial support to establish a training base of professional. In the specific teaching of the specialty, colleges and universities should actively strengthen the cooperation between schools and enterprises, in the large platform of school-enterprise cooperation in the full implementation of the road of production and research cooperation, combined with the development of modern science and technology on the professional curriculum effective scientific Development and set up, some of our vocational colleges in the school to build the bio-engineering technology research center for the students of professional courses and practical training to create a 
good condition. In addition, some institutions have built a training base in the school, in the specific training program to meet the needs of the community's pharmaceutical companies to set up courses and skills training, training base in the technology center not only to achieve their own production, But also to external processing, and fully meet the practical needs of student entrepreneurship training [2].

Some institutions in the pharmaceutical production technology professionals to effectively establish a professional engineer with industry engineers and industry experts, and for the professional course of teaching to hire an experienced part-time teacher to promote the dual-type faculty, set up specifically for the experts and teachers Of the studio and the laboratory, making the pharmaceutical production technology professional courses to learn the theoretical knowledge and practice teaching integration of teaching places. In the course of professional courses, colleges and universities have formulated the subsidy system of related training funds based on the actual situation, so as to further strengthen the financial support for the cultivation of innovation and entrepreneurship in higher vocational colleges. In addition to the professional teaching in the amount of the establishment of the school and enterprise jointly manage the common education system, a comprehensive vocational colleges in the pharmaceutical production technology to meet the modern apprenticeship training model requirements [3].

In recent years, many colleges and universities and the local outstanding pharmaceutical companies were joint in the pharmaceutical production technology professional enrollment in a comprehensive start of the order class enrollment work, and to strengthen the professional training of students, schools and enterprises in accordance with their own development The need to develop the corresponding enrollment brochures, enterprises in the professional curriculum teaching actively participate in the curriculum system to build the work, and further promote the practice of enterprise recruitment system and the corresponding two-tutor teaching model to be fully implemented. In the country put forward the modern apprenticeship training model under the premise of the positive work of the model to start the specific work experience to sum up and accumulate, so as to effectively improve the vocational colleges of pharmaceutical production technology teachers and students of the ideological understanding.

\section{The Empirical Analysis of Modern Apprenticeship Training Model}

At present, many of our vocational colleges belong to underdeveloped areas. There are not many pharmaceutical enterprises in the integrated areas. Each year, the number of graduate students in the pharmaceutical industry in these areas is much higher than that provided by the enterprises in the society. In this case, Of the pharmaceutical companies do not want to start in college teaching enrollment and recruitment of the enrollment model, do not want to take this model brought about by the obligations and responsibilities of vocational colleges and universities in the implementation of the joint training of school work is not willing to bear. In view of the actual situation of our school, the pilot enterprises of our school Mentholatum (China) Pharmaceutical Company, in the teaching to take the $1.5+0.5+0.5+0.5$ way, that is, the first three semesters in the school mainly learning general course, Professional basic course and some specialized courses; the first 0.5 is the fourth semester, is the combination of work and study, the implementation of mentoring teaching methods, not only the implementation of professional skills teaching, but also through the two sides set up self-awareness, workplace entry, environmental adaptation, skills development Four quality ability to enhance class courses, through this training, not only to develop the students professional skills, more valuable is to make the students' professional accomplishment has been greatly improved; the second 0.5 is the fifth semester, the students through the combination of work and study, After the teacher's teaching session, and then return to the school to continue to study the core course of professional courses, when the purpose of learning more clearly, learning to improve the enthusiasm of the last 0.5 is the sixth semester, is the internship stage, Pre-preparation, student learning ability and adaptability are enhanced, will soon be able to adapt to the post, by the employer .

At present, the modern apprenticeship system is applied in the pharmaceutical production 
technology specialty of higher vocational colleges in our country. In fact, the traditional apprenticeship system and the school education system are effectively and rationally reorganized. In the actual teaching process, the specific object of teaching is the dual identity of students and workers [4]. Vocational colleges should actively combine the specific characteristics of the development of local pharmaceutical enterprises in the school launched the "school factory" teaching model, a comprehensive understanding of the pharmaceutical enterprises in the university personnel training mode of professional guidance and put forward effective training proposals to strengthen Enterprises and vocational colleges in-depth cooperation in the teaching process of the full implementation of the two-teacher teaching model, the social pharmaceutical companies actively sent to the "school factory" in the teaching platform for student job skills training guidance, The students from the basic ability to high-quality professional ability to cultivate, so as to fully meet the social pharmaceutical enterprises on the needs of professional talents, and effectively solve the vocational college students in the production of technical students graduation pressure, in the fundamental to establish act as an effective modern apprenticeship training model.

In the vocational colleges, the students' ability to innovate in a large extent depends on the teacher's actual teaching. In the course of professional teaching, teachers should actively play their own guiding role. Students should carry out specific experiments under the guidance of teachers. Research work, in this process will certainly be the teacher in the scientific research methods, style and ideas of the impact, so as to the students' innovative ability to carry out a comprehensive training [5]. In addition, in the professional teaching process teachers should actively guide students in the subject of the subject on the innovative research activities to conduct a comprehensive, and further promote the cultivation of students to improve and strengthen the ability to innovate. There are many still in the entrepreneurial stage of the pharmaceutical companies to strengthen cooperation with these enterprises on the cultivation of students' ability to play a very critical role. Students in the professional learning process and the common experience of innovation in the production and sale of drugs, such as the entire business of the difficult process, greatly promote the students' innovative ability to improve the overall business.

\section{The Development of Modern Apprenticeship Training Model in the Existing Problems and Solutions}

In the vocational school of pharmaceutical production technology teaching in the implementation of school-enterprise co-management model is a comprehensive basis for the development of the interests of enterprises in the teaching mode of the activities of the activities if the enterprise did not get a higher interest or not Will get any benefits, schools and enterprises of this form of cooperation has not been legally guaranteed by the law, this teaching model is likely to not have a high degree of continuity, the enterprise in this process is likely to lose the interest of cooperative education and enthusiasm [6]. In the case of a decline in the market economy, companies may no longer participate, so that the whole school co-management model will stop. And in this situation after the effective solution is that schools and enterprises in the model at the beginning of the establishment of legislation to strengthen the work, so that the entire teaching activities in the process of expanding the law, the whole school co-management activities continue to be able to fully protected.

In the vocational colleges of the pharmaceutical production technology innovation and entrepreneurship education can not just stay in the form of the above, but should be carried out in a practical practice. Both the educational institutions and institutions in the specific teaching should show the actual work of specific teaching performance, the completion of this work must have the appropriate funding to support and funding, or vocational colleges in the start of innovative entrepreneurship teaching is not We will achieve substantial results. But in the course of teaching in the end to the funding, the number of funds to the number, and how to ask the funding and other issues are worthy of college attention [7]. Now a lot of colleges and universities for the pharmaceutical production technology innovation and entrepreneurship teaching still remain in the game, hanging and other external forms, is not conducive to the entire educational and efficient 
development. This situation is a favorable solution after the teacher's research funding into the specific innovation and entrepreneurship teaching, different financial departments should actively strengthen the investment of funds to encourage students to actively enter the pharmaceutical business in entrepreneurial practice. At present, we will implement effective modern apprenticeship training mode in the pharmaceutical production technology specialty of higher vocational colleges in our country. One of the most important links is to carry out the specific work of enrollment and recruitment. This work is in the process of implementation and enterprise employees teaching management had a certain conflict [8]. The main reason for this situation is that enterprises still follow the traditional ideas in the specific cultural construction, and did not combine the characteristics of the times to carry out the comprehensive introduction of the new ideas and ideas. The employees of the enterprise should introduce different work in the work team management Personnel, only in this practical situation in order to ensure that the enterprise will appear within the small interests of the emergence of groups, but also on the aging of corporate employees think of the phenomenon of effective eradication, and comprehensively enhance the vitality of enterprise operation and development. Enterprises in the recruitment of personnel in order to prevent the emergence of workers from the same school, the joint recruitment of recruitment enterprises should be actively engaged in continuous changes in this case, vocational colleges need to invest a considerable part of the human and material resources and financial resources, need to get government finance Expenditure support, or it is difficult to start the corresponding activities [9]. The way to deal with this situation is that the vocational colleges only cooperate with the industry associations to strengthen the establishment of professional committees in the process of cooperation, so as to form a relatively stable form of production and research, and actively carry out research work according to actual needs To carry out, for the specific development of enterprises recommended appropriate professional talents.

\section{Conclusion}

To sum up, to further promote the production of modern drug apprenticeship training model is to cultivate the needs of social enterprises to meet the professional needs of professionals, to strengthen the modern science and technology and the cultivation of modern scientific knowledge of students is the core of modern apprenticeship Content, and effectively strengthen the students' innovative entrepreneurial ability. This paper focuses on the advancement of modernized apprenticeship training mode in our country, and carries out the experience of modernized apprenticeship personnel training mode in higher vocational colleges. There are three problems and solutions in modernized apprenticeship training mode in higher vocational colleges The main aspects of the analysis, hoping to comprehensively in the context of the integration of production and education under the comprehensive construction of scientific and rational high vocational drug production technology professional modern apprenticeship training model for Chinese pharmaceutical enterprises to develop professional and practical high-quality talent, further To promote Chinese pharmaceutical companies to be smooth and healthy operation and development.

\section{References}

[1] Zhang Kai-tao.Study on professional accomplishment of vocational college students based on the mode of integration of production and education - Taking the professional accomplishment cultivation of modern logistics management specialty of logistics management specialty [J].Education and teaching forum, 2014, 53: 233-234

[2] Fan Li, Zhu Yongxiang.Study on the Construction of Talent Training System Based on "Integration of Production and Teaching, School-Enterprise Cooperation" - Taking Nantong Shipping Vocational and Technical College as an Example [J]. Journal of Nantong Vocational College of Shipping, 2015, 01: 77-81

[3] Lu Yi, Wang Xiaojuan, Kuang Wangqiu. Pharmaceutical production technology in vocational 
colleges bridging curriculum system construction - the direction of drug preparation as an example [J]. Macroeconomic management, 2017, S1: 142-143 +454

[4] Jiang Xinge, Xue Shengnan, Xu Aijun. Analysis on the Characteristics of the Operation System of the Double Teachers' Studio in Higher Vocational Colleges [J]. Vocational and Technical Education, 2016, 26: 8-12

[5] Li Yongjian, Guan Wei. Integration of production and education under the new model of personnel training in vocational colleges - Taking Guangdong Agricultural and Commercial Vocational and Technical College as an example [J]. Liaoning Vocational Journal, 2017,01: 13-17.

[6] Guo Ju, Jia Linping, Zhang Zhenying, Yu Jiang. Study on Cooperative Practice Teaching Mode of E-commerce Specialty in Higher Vocational Education [J]. Journal of Beijing Economic Management Vocational College, 2016,02: 59-63.

[7] He Wenhua, Tang Jianxiong, Xing Dacheng.Study on the Training Model of Productive Training Talents Based on "Dual Entity" - Taking Higher Vocational and Commercial Majors as an Example [J]. Higher Education Exploration, 2017,04: 92-96.

[8] Yao Na, Guo Youfeng, Wang Jianming, Xu Manjiao. Secondary vocational examination of professional and educational integration of teaching methods of the effect of analysis [J]. Guangdong Vocational and Technical Education and Research, 2017,02: 96-97.

[9] Wu Lei, Zhang Lijun, Chen Xiangfen, Wang Jingyan, Liu Xiaowei. Modern business professional group construction theory and practice research - based on "333" combination of work and study talent training model [J]. Northern trade, 2017,04: 135-137 + 153 